\title{
Imposto de Importação e Evasão Fiscal: Uma Investigação do Caso Brasileiro*
}

\author{
Maria da Conceição Sampaio de Sousa ${ }^{\dagger}$, Maria Eduarda \\ Tannuri-Pianto ${ }^{\ddagger}$, Carlos Antônio Silva dos Santos ${ }^{\S}$
}

Sumário: 1. Introdução; 2. Comércio internacional e evasão fiscal: o modelo de Fisman e Wei (2004); 3. Dados e estatísticas descritivas; 4. Resultados; 5. Conclusão.

Palavras-chave: Evasão Fiscal; Alíquotas Tarifárias; Sistema Tributário.

Códigos JEL: H26, H21, F13.

Este trabalho mensura o impacto das alíquotas do imposto de importação sobre a evasão fiscal nas importações brasileiras oriundas dos Estados Unidos. Os resultados obtidos permitem concluir que as alíquotas tarifárias influenciam a evasão sob suas diferentes formas: subfaturamento e classificação incorreta de mercadorias. Estes resultados corroboram o modelo básico de evasão proposto por Allingham (1972) e se insere no debate sobre a relação entre a magnitude das alíquotas e o potencial para evasão. Nossos resultados mostram, ainda, a existência de não linearidades na relação entre alíquotas e evasão. Nos vários modelos testados, esse efeito cresce com a magnitude das tarifas, sugerindo que maiores alíquotas aumentam o custo de oportunidade da tributação e geram maiores incentivos para a sonegação. Por fim, com respeito à relação entre o nível de complexidade da estrutura tributária e a evasão, nosso trabalho sugere que uma maior diferenciação entre alíquotas, dificulta a administração tarifária e pode levar a evasão.

In this paper we measure the effect of tax rates on tax evasion using data on the trade flow between Brazil and the United States. Our results show that increases in the tax rates lead to higher evasion on two different ways: under invoicing and mislabeling higher taxed products as lower ones. These results

\footnotetext{
* Gostaríamos de agradecer Donald Pianto por valiosos comentários e pelo suporte computacional na construção das variáveis. ${ }^{\dagger}$ Departamento de Economia, Universidade de Brasília. CEP: 70910-900, Brasília - DF - Brasil. Tel/fax: 55-61-33072498; e-mail: mcss@unb.br.

${ }^{\ddagger}$ Departamento de Economia, Universidade de Brasília. CEP: 70910-900, Brasília - DF - Brasil. Tel/fax: 55-61-33072498; e-mail: tannuri@unb.br.

§Universidade de Brasília/ESAF. CEP: 70910-900, Brasília - DF - Brasil. Tel/fax: 55-61-33072498; e-mail: Carlos.Santos $@$ desenvolvimento.gov.br.
} 
corroborate the theoretical predictions of the Allingham (1972) model and contribute to the recent debate on the influence of tax rates on evasion. We also point out to the existence of nonlinearities in the relationship between tax rates and evasion by showing that higher rates raise the opportunity costs of paying taxes and thus encourage evasion. Finally, our results suggest that relatively high rates and a complex set of rules, especially for customs taxes, result in large potential rewards for taxpayers willing to bribe to cut their own tax burden and/or speed up customs clearance of their goods.

\section{INTRODUÇÃO}

A maioria das análises sobre tributação presume que a arrecadação pode ser apurada e coletada sem custos. Contudo, quando tal assunção é confrontada com a realidade, torna-se patente sua fragilidade. Isto porque, a existência de evasão fiscal é amplamente disseminada, particularmente, nos países em desenvolvimento, onde tanto a eficiência da coleta de impostos como os mecanismos de imposição tributária são precários (Alm et alii, 1991). Ademais, essas práticas têm efeitos deletérios sobre a eficiência econômica e envolvem redistribuições arbitrárias e indesejadas de renda (Hindriks et alii, 1999, Slemrod e Bakija, 1998). Portanto, esforços para reduzir a evasão devem constar de programas de reformas econômicas que visam à estabilização econômica e o equilíbrio das finanças públicas. Para tal, é preciso investigar os determinantes da sonegação.

Estudos recentes mostram que a evasão é influenciada por comportamentos do tipo rent seeking e pelo nível de corrupção das economias (Burgess e Stern, 1993). Modelos calcados no trabalho seminal de Allingham (1972), doravante referido como modelo A-S, destacam o papel dos incentivos para a eclosão da sonegação (Yitzhaki, 1974, 1979, Mayshar, 1991, Andreoni, 1992). Esses modelos postulam que a existência de alíquotas elevadas, ao aumentar o prêmio para a evasão, estimula a sonegação. Ainda no âmbito desses modelos, a existência de fortes penalidades para os infratores bem como uma alta probabilidade de detecção desencorajam a evasão. Estudos subseqüentes sugerem que se uma maior probabilidade de detecção contribui, indubitavelmente, para a redução da evasão, corroborando, assim, os resultados do modelo A-S, o mesmo não ocorre, porém, no tocante à relação entre alíquotas e a evasão fiscal. Nesse ponto, a evidência empírica não é conclusiva. Slemrod e Yitzhaki (2002), em ampla revisão da literatura sobre o tema, apontam para o fato de que a relação entre a magnitude das alíquotas e o nível de sonegação depende das hipóteses adotadas em cada modelo e, portanto, não se presta a generalizações. A relação positiva entre alíquotas e evasão é, pois, fundamentalmente, uma questão empírica. $O$ cerne da discussão passa a ser a estimação da elasticidade da evasão em relação às alíquotas. É nesse contexto, que se insere nosso trabalho.

Embora a maioria dos trabalhos sobre evasão centre-se na tributação da renda, alguns autores utilizaram o quadro teórico do modelo A-S para examinar a evasão de impostos indiretos (Marrelli e Martina, 1988). Em particular, no que diz respeito ao imposto de importação, vários trabalhos chamam a atenção para o potencial de sonegação no âmbito desse tributo (de Melo et alii, 1992, Arndt e Tarp, 2004). Nos países em desenvolvimento, a evasão, facilitada pela existência de tarifas elevadas e uma estrutura tarifária complexa pontuada por uma miríade de isenções, reduz, significativamente, a receita arrecadada com o imposto de importação e desvincula as tarifas efetivas das alíquotas legais (Tsikata, 1999, Pritchett e Sethi, 1994). Nesse contexto, não é, pois, surpreendente, a existência de diferenças significantes entre as alíquotas legais e aquelas efetivamente aplicadas. De fato, para os principais tributos, uma resenha de vários trabalhos sugere que o valor atingido pela evasão fiscal representa uma parcela substancial da arrecadação. Recentemente, Fisman e Wei (2004) investigaram o impacto das alíquotas sobre a evasão, no comércio bilateral entre Hong Kong e a China e concluíram que a sonegação está fortemente correlacionada com aumentos nas alíquotas. Para eles, tarifas elevadas encorajam a evasão por 
três vias distintas: favorecem o subfaturamento das importações, a classificação, deliberadamente, incorreta das importações e a sub-declaração das quantidades importadas. Esses autores sugerem, ainda, que as elevadas tarifas adotadas pela China estariam colocando esse país na parte descendente da curva de Laffer, onde aumentos nas alíquotas reduziriam, ao invés de aumentar, a arrecadação.

No Brasil, apesar da liberalização do comércio ocorrida nos início dos anos 90, a estrutura tarifária é, ainda, bastante complexa. Alíquotas diferenciadas e relativamente elevadas coexistem com inúmeras isenções e regimes especiais, resultando em níveis significantes de dispersão. Trata-se, pois, de um contexto, particularmente, apropriado, para o surgimento da evasão. Embora não existam, a nosso conhecimento, trabalhos que estimam a magnitude da evasão do imposto de importação, é razoável supor que o sistema tarifário, inserido no caótico sistema tributário nacional, presta-se bem à sonegação, como sugerem notícias freqüentes na imprensa, envolvendo grandes importadores, que, supostamente, teriam sido flagrados praticando evasão. Ademais, se a redução tarifária que vem ocorrendo no Brasil, ao reduzir as alíquotas, reduzir também o incentivo à fraude fiscal, então, dependendo da magnitude desse efeito, esse corte nas tarifas não implica, necessariamente, uma menor arrecadação com o imposto de importação. Para responder essas e outras questões, é importante, avaliar a influência da estrutura tarifária sobre a sonegação.

O objetivo desse trabalho é, pois, investigar o impacto das tarifas sobre a evasão fiscal nas importações brasileiras oriundas dos Estados Unidos da América. A escolha dos EUA teve como determinantes os seguintes aspectos:

1. (i) o fato de ser um parceiro comercial tradicional, o que minimiza muitos problemas relacionados com a compatibilidade dos dados;

2. (ii) a magnitude da pauta de exportação dos EUA para o Brasil, relativamente aos demais parceiros;

3. (iii) a disponibilidade de dados. Para tal, utilizaremos uma abordagem similar àquela desenvolvida por Fisman e Wei (2004).

Trata-se de um estudo pioneiro, que pode contribuir para o debate sobre sonegação no Brasil e em outros países e ajudar a estabelecer parâmetros quantitativos para essa discussão.

Este trabalho está organizado da seguinte maneira. A Seção 1 introduz o problema da evasão fiscal e discute brevemente a literatura que investiga o impacto das alíquotas sobre a evasão fiscal. A Seção 2 apresenta e discute a metodologia utilizada por Fisman e Wei (2004) para mensurar a evasão tarifária. A Seção 3 descreve a base de dados e apresenta estatísticas descritivas e a Seção 4 apresenta e discute os resultados econométricos. Finalmente, a Seção 5 reúne as principais conclusões do trabalho.

\section{COMÉRCIO INTERNACIONAL E EVASÃO FISCAL: O MODELO DE FISMAN E WEI (2004)}

O modelo de Fisman e Wei (2004) utiliza o conjunto de produtos da pauta comercial, considerando um elevado nível de desagregação (seis dígitos), do Código de Nomenclatura de Produtos do Sistema Harmonizado $(\mathrm{SH})^{1}$ para construir uma medida de sonegação baseada nas discrepâncias existentes entre os dados de comércio na origem e no destino. A idéia básica desse modelo é confrontar o valor das importações do país A, oriundas de um determinado país B, com o valor das exportações do país B para o país A. Parte-se, então, das discrepâncias entre estes valores para caracterizar a existência de evasão fiscal e verificar a existência de relação entre estas discrepâncias e a alíquota do imposto de importação do país A. No modelo, essas discrepâncias, servem como uma proxy para a evasão (gap), definida como:

${ }^{1}$ O Sistema Harmonizado de Designação e de Codificação de Mercadorias, ou simplesmente Sistema Harmonizado (SH), é um método internacional de classificação de mercadorias, baseado em uma estrutura de códigos e respectivas descrições. 


$$
G A P_{i}=\log \left(E_{i}\right)-\log \left(M_{i}\right) ;
$$

onde $\log \left(E_{i}\right)$ é o logaritmo natural do valor das exportações do país B, e $\log \left(M_{i}\right)$ é o logaritmo natural do valor das importações do país A, referentes ao i-ésimo produto. O ponto central aqui é investigar se, em razão da existência de evasão, a diferença expressa pela equação 1 é crescente com as alíquotas tarifárias.

$$
G A P_{i}=\beta_{0}+\beta_{1} \tau_{i}+\epsilon_{i}
$$

onde $\beta_{0}$ é uma constante e $\epsilon$ é um vetor de erros. O índice $i$ denota o produto e $\tau_{i}$ representa a alíquota média de importação sobre o i-ésimo bem a 6 dígitos. Se, como indicado pelos modelos clássicos de evasão, o gap aumentar com as alíquotas, então $\beta_{1}>0$. Supõe-se, inicialmente, que a evasão se faz mediante o subfaturamento das importações, uma forma tradicional de evasão. Uma outra maneira comum de sonegar o imposto de importação advém da classificação incorreta de mercadorias (mislabeling), na qual um produto de alíquota elevada é, deliberadamente, classificado como se fosse outro de alíquota inferior, para reduzir a carga tributária.

Para testar a existência desse tipo de evasão, (Fisman e Wei, 2004) incluíram como regressor a alíquota média dos produtos similares ao produto i, definidos como todos os demais produtos incluídos na mesma categoria do i-ésimo produto (classificação $\mathrm{SH}$, em nível de quatro dígitos, que corresponde à posição do produto). Espera-se que os coeficientes atrelados a essa variável sejam negativos. Isto porque, para o i-ésimo bem, quanto menor for a alíquota de produtos que lhes são similares, maior será o incentivo para que ele seja, de forma deliberada, declarado erroneamente. Nesse caso, a expressão (2) torna-se:

$$
G A P_{i}=\beta_{0}+\beta_{1} \tau_{i}+\beta_{2} \tau_{-} \operatorname{sim}_{i}+\epsilon_{i}
$$

onde a variável $\tau_{s} i m_{i}$ que capta a evasão por classificação incorreta, foi construída de duas formas:

1. (i) como a alíquota média, ponderada pelo valor das exportações, dos produtos similares ao iésimo produto;

2. (ii) como a tarifa mínima entre todos os produtos similares ao i-ésimo produto.

Cabe ressaltar que, se a classificação incorreta de bens prevalece, espera-se que $\beta<0$, uma vez que mantendo-se a tarifa do bem i constante, quanto menor a tarifa do seu similar, maior o incentivo para se classificar incorretamente e, conseqüentemente, maior o gap de evasão referente ao i-ésimo bem.

Note-se, ainda, que a evasão pode ser influenciada não somente pela magnitude, mas também pela complexidade da estrutura tarifária (Kaplow, 1996, Tsikata, 1999, Pritchett e Sethi, 1994). Um sistema em que alíquotas diferenciadas coexistem com uma miríade de isenções e regimes especiais, oferece um ganho potencial maior para os contribuintes dispostos a burlar as regras fiscais para reduzir a sua carga tributária e, portanto, presta-se mais facilmente a práticas como a evasão e a elisão fiscal. ${ }^{2}$ Para levar $^{2}$ em conta esses aspectos, incluímos no modelo de Fisman e Wei, alternativamente, (i) o desvio padrão das alíquotas tarifárias, dentro da categoria de quatro dígitos, do sistema SH, (equação 4) e, (ii) uma medida da amplitude das tarifas, definida como a diferença entre a maior e a menor alíquota, também dentro de cada categoria de quatro dígitos, do sistema $\mathrm{SH}$, denominada $\tau$ - amplit (Equação 5). Nesse caso, a equação (3) torna-se:

$$
G A P_{i}=\beta_{0}+\beta_{1} \tau_{i}+\beta_{2} \tau_{s} i m_{i}+\beta_{3} \sigma_{i}^{2}+\epsilon_{i}
$$

\footnotetext{
${ }^{2}$ Contrariamente a evasão fiscal, que constitui infração à legislação tributária, a prática da elisão fiscal é parte do planejamento tributário das empresas e, portanto é lícita e legítima. Em nosso trabalho, trataremos apenas da questão da evasão fiscal.
} 


$$
G A P_{i}=\beta_{0}+\beta_{1} \tau_{i}+\beta_{2} \tau_{s} i m_{i}+\beta_{4} \tau_{a} m p l i t_{i}+\epsilon_{i} ;
$$

Espera-se que os coeficientes $\beta_{3}$ e $\beta_{4}$ sejam positivos. Uma dispersão maior bem como uma maior amplitude das alíquotas, dentro de uma mesma classificação tarifária, estimularia a sonegação, uma vez que o contribuinte tem a percepção, de que é mais difícil para a autoridade tributária administrar diferentes alíquotas para produtos muito parecidos.

Finalmente, podemos fazer uma analogia com o modelo teórico A-S, de acordo com o qual, quanto mais rico o indivíduo, maior o estímulo à evasão. Assim, quanto maior o fluxo de comércio, maiores seriam as possibilidades de evasão, controlando-se para os demais fatores que influenciam o gap fiscal. Para levar em conta esse efeito escala, introduzimos uma variável que mede a importância relativa de cada produto no fluxo comercial. Acrescentando-se essa variável - denominada $\theta_{i}$ e definida como a participação das exportações do i-ésimo produto nas exportações totais - a expressão acima reescreve-se como:

$$
G A P_{i}=\beta_{0}+\beta_{1} \tau_{i}+\beta_{2} \tau_{s} i m_{i}+\beta_{4} \tau_{a} m p l i t_{i}+\beta_{5} \theta_{i}+\epsilon_{i} ;
$$

onde espera-se que $\beta_{5}>0$. As equações (2) a (6) descrevem o modelo que será testado empiricamente na Seção 4.

\section{DADOS E ESTATÍSTICAS DESCRITIVAS}

A construção da base de dados utilizou duas fontes:

1. (i) a Commodity Trade Statistics Database (COMTRADE), mantida pela United Nations Statistic Division (UNSD);

2. (ii) o Trade Analysis and Information System (TRAINS), mantido pela United Nation Conference on Trade and Development (UNCTAD).

O acesso aos dados de ambas as fontes foi viabilizado por meio do software World Integrated Trade Solution (WITS), desenvolvido pelo Banco Mundial em colaboração com a UNCTAD. As bases de dados COMTRADE e TRAINS forneceram informações, respectivamente, sobre:

1. (i) o valor dos fluxos comerciais (exportações norte-americanas para o Brasil e importações brasileiras oriundas dos EUA);

2. (ii) as tarifas de importações aplicadas pelo Brasil no comércio com os EUA.

Nas duas fontes, os dados são informados por ano e por produto, sendo que o nível de especificação mais desagregado do produto é de seis dígitos, conforme o Sistema Harmonizado de Nomenclatura $(\mathrm{SH}){ }^{3}$

Para o presente estudo foram utilizados dados (valor e tarifa) por produto ao nível de seis dígitos, com base no SH, referentes aos anos de 1998, 1999, 2000, 2001, 2002 e 2003, o que pode ser considerado um elevado nível de desagregação, com aproximadamente 4000 observações (produtos) por ano. Notese que os dados relativos ao valor dos fluxos comerciais são informados com base em INCOTERMS (International Comercial Terms) ${ }^{4}$ distintos: (i) o valor das exportações norte-americanas para o Brasil

\footnotetext{
${ }^{3}$ Deve-se ressaltar que os países podem desenvolver versões mais refinadas de classificação, com base no SH. Por exemplo, o sistema de nomenclatura adotado pelo Mercosul, Nomenclatura Comum do Mercosul (NCM), possui oito dígitos, sendo que os seis primeiros obedecem o $\mathrm{SH}$.

${ }^{4}$ Os Incoterms (International Commercial Terms / Termos Internacionais de Comércio) definem os direitos e obrigações recíprocas do exportador e do importador, dentro de um contrato de compra e venda internacional, estabelecendo um conjunto-padrão de definições e determinando regras e práticas.
} 
é informado no termo Free Alongside Ship (FAS), livre ao longo do costado do navio; e (ii) o valor das importações brasileiras oriundas dos EUA é informado no termo Free On Board (FOB), livre abordo do navio. ${ }^{5}$

Conforme mencionado anteriormente, em tese, os valores das exportações na origem deveriam ser iguais ao valor das importações no destino, uma vez que as exportações de B para A são as importações de A, oriundas de B. Mas isto não é o que ocorre. Ao analisar os dados, verificam-se diferenças significativas, tanto nos valores agregados quanto em nível de produto. Em geral, estas discrepâncias são tomadas como erros de mensuração. Contudo, estudos empíricos indicam um alto grau de correlação entre essas diferenças e as alíquotas do imposto de importação, aplicadas no país de destino. Isso possibilita caracterizar e mensurar a existência de evasão fiscal nas importações, seja por subfaturamento ou por classificação incorreta de mercadorias. Cabe ressaltar que toda análise até aqui desenvolvida pressupõe como "corretas"as informações reportadas pelos EUA (Exportações dos Estados Unidos destinadas ao Brasil), enquanto àquelas constantes dos controles governamentais brasileiros (Importações brasileiras provenientes dos Estados Unidos) absorvem (capturam) a tentativa dos importadores de fugir da ação do fisco, por meio dos mecanismos já mencionados (subfaturamento e classificação incorreta).

Note-se, por fim, que diversos autores (De Wulf, 1981, Anson et alii, 2003, Feenstra e Hanson, 2000) fazem ressalvas à forma de mensurar a sonegação adotada por Fisman e Wei (2004). Segundo estes autores, este hiato entre os valores informados na origem e no destino incorporam muitos outros comportamentos, além da prática de sonegação, como por exemplo, diferentes sistemáticas de reportar as exportações e as importações, com diferentes níveis de comprometimento com a informação declarada e erros de mensuração. A Tabela 1 apresenta as estatísticas descritivas para essas variáveis, para 0 período 1998-2003.

\section{RESULTADOS}

Os modelos empíricos estimam os coeficientes das Equações (2) a (6). Os resultados, são apresentados nas Tabelas 2 a 5. Aproveitamos a estrutura longitudinal de nossa amostra e estimamos modelos de efeitos fixos e aleatórios. Em todas as especificações estudadas o teste de Hausman aponta para a validade do modelo de efeitos fixos. Aplicamos também testes para autocorrelação de primeira ordem dos erros idiossincráticos $u_{i t},{ }^{6}$ robustos à heterocedasticidade, e rejeitamos a hipótese nula de ausência de autocorrelação para todos os modelos estimados. Entretanto, apesar do coeficiente de autocorrelação de primeira ordem ser positivo, ele é bastante baixo, $\rho=0,08$ ou 0,09 , em todos os modelos estimados. Assim sendo, optamos por utilizar o modelo de efeitos fixos ( $\mathrm{EF}$ ) ao invés do modelo de primeiras diferenças (PD), já que estamos muito mais próximos de um coeficiente de autocorrelação serial igual a zero do que de um coeficiente igual a um (passeio aleatório), situação na qual o modelo PD seria mais eficiente. Efetuamos também testes para a hipótese de exogeneidade estrita (Wooldridge, 2002, p.285) e concluímos que essa é uma hipótese plausível, já que não pôde ser rejeitada em nenhuma das especificações. Reportamos erros-padrão robustos a autocorrelação e heterocedasticidade para todos os modelos estimados.

A Tabela 2 apresenta os resultados para o modelo básico, expresso pela Equação (2). Na coluna (A), que servirá de referencial, o coeficiente positivo e significante associado à alíquota do imposto de importação mostra que alíquotas mais elevadas estimulam a evasão e resultam em gaps maiores, uma vez que o custo de oportunidade de não sonegar aumenta. 0 valor para esse coeficiente indica que 0

\footnotetext{
${ }^{5}$ O No termo FOB (Free on Board), o vendedor encerra suas obrigações quando a mercadoria transpõe a amurada do navio (ship's rail) no porto de embarque. Já no FAS (Free Alongside Ship), o vendedor encerra suas obrigações no momento em que a mercadoria é colocada ao lado do navio transportador, no cais ou em embarcações utilizadas para carregamento, no porto de embarque designado.

${ }^{6}$ Chamamos de $a_{i}+u_{i t}$ os erros em composição do modelo de painel, com $a_{i}$ representando a heterogeneidade não-observada e $u_{i t}$ o componente idiossincrático do erro.
} 
Tabela 1 - Estatísticas descritias, por ano, das principais variáveis

\begin{tabular}{|l|c|c|c|c|c|c|}
\hline \multirow{2}{*}{ Variáveis } & \multicolumn{5}{|c|}{ Anos } \\
\cline { 2 - 7 } Valor Gap & 1998 & 1999 & 2000 & 2001 & 2002 & 2003 \\
média & & & & & & \\
desvio-padrão & $-1,06$ & $-1,07$ & $-1,05$ & $-1,14$ & $-1,22$ & $-1,18$ \\
min & 3,91 & 4,03 & 4,06 & 4,09 & 4,11 & 4,05 \\
max & $-19,40$ & $-18,91$ & $-18,82$ & $-18,79$ & $-18,89$ & $-16,01$ \\
\hline Alíquota- $\tau$ (6 dígitos) & 12,79 & 15,90 & 15,60 & 14,31 & 13,56 & 15,07 \\
média & & & & & & \\
desvio-padrão & 16,42 & 16,11 & 15,85 & 14,32 & 13,97 & 13,68 \\
min & 6,34 & 5,98 & 5,84 & 6,37 & 5,90 & 5,75 \\
max & 0,00 & 0,00 & 0,00 & 0,00 & 0,00 & 0,00 \\
\hline Alíquota Similar (4 dígitos) & 49,00 & 35,00 & 35,00 & 36,50 & 36,00 & 36,00 \\
média & & & & & & \\
desvio-padrão & 16,11 & 15,78 & 15,51 & 13,90 & 13,66 & 13,36 \\
min & 6,24 & 5,90 & 5,71 & 6,18 & 5,70 & 5,56 \\
max & 0,00 & 0,00 & 0,00 & 0,00 & 0,00 & 0,00 \\
\hline Alíquota Mínima Similar (4 dígitos) & 49,00 & 35,00 & 35,00 & 35,00 & 35,00 & 35,00 \\
média & & & & & & \\
desvio-padrão & 14,30 & 14,06 & 13,87 & 12,09 & 11,91 & 11,58 \\
min & 6,73 & 6,60 & 6,53 & 7,09 & 6,66 & 6,46 \\
max & 0,00 & 0,00 & 0,00 & 0,00 & 0,00 & 0,00 \\
\hline Amplitude Alíquota (4 dígitos) & 49,00 & 35,00 & 35,00 & 35,00 & 35,00 & 35,00 \\
média & & & & & & \\
desvio-padrão & 4,02 & 3,91 & 3,73 & 4,55 & 4,00 & 4,08 \\
min & 5,71 & 5,34 & 4,97 & 5,90 & 5,53 & 5,50 \\
max & 0,00 & 0,00 & 0,00 & 0,00 & 0,00 & 0,00 \\
\hline N. obs & 31,00 & 24,40 & 22,80 & 32,00 & 34,00 & 34,00 \\
\hline
\end{tabular}

aumento de um ponto percentual na alíquota leva ao aumento de 3,8 por cento na evasão, mensurada pelo valor do gap de evasão.

Vamos passar, agora, à análise da evasão mediante o uso de classificação incorreta (mislabeling) que consiste em declarar um produto fortemente tributado como uma mercadoria semelhante, porém, sobre a qual incide uma tarifa menor. Na Tabela 2 (coluna B) incluímos como variável explicativa adicional, a alíquota sobre produtos similares, alíquota média do similar $(\tau-\operatorname{sim})$. Essa alíquota foi definida como a média das alíquotas de todos os outros bens dentro da classe de quatro dígitos, ponderada pelo valor da exportação americana correspondente.

Os resultados expostos na Tabela 2 atestam a existência, no Brasil, de sonegação do imposto de importação mediante o uso da classificação incorreta de mercadorias. O coeficiente estimado para a variável Alíquota Média do Similar $\left(\tau_{s} i m\right)$ é, conforme esperado, negativo e significante. Alíquotas mais baixas para produtos similares aumentam, pois, o custo de oportunidade de classificar corretamente a i-ésima mercadoria. Note-se, ainda, que a inclusão da alíquota sobre produtos similares aumenta, substancialmente, o coeficiente da variável alíquota média elevando, assim, a evasão via subfaturamento. Isto ocorre porque, na ausência da variável que capta a tributação sobre artigos similares, o coeficiente referente á alíquota média do produto $i$ capta tanto a evasão por subfaturamento como aquela decor-

RBE Rio de Janeiro $\quad$ v. 62 n. 1/p. 77-93 Jan-Mar 2008 
rente da classificação incorreta. Ora, essa variável é positivamente correlacionada com a alíquota média do similar (tanto em nível como em diferenças) e, a sua redução contribui para o aumento da evasão (via classificação incorreta). A magnitude do coeficiente de alíquota média do produto aumenta de 0,038 para 0,074 com a inclusão da alíquota média do similar no modelo, já que deixa de captar ambos os efeitos, que apresentam sinais contrários, explicando, assim, a redução do coeficiente atrelado à alíquota média do produto.

As colunas (C) e (D) visam captar a existência de não linearidades na relação entre a evasão e as alíquotas tarifárias. Isso porque, é razoável supor que existem custos fixos associados à evasão. Essa hipótese é consistente com o fato de que a probabilidade de detecção não varia com as alíquotas, mas depende da existência de mecanismos de controle, fixados pelas autoridades responsáveis pela fiscalização, bem como da eficácia desses mecanismos. Nesse caso, para alíquotas mais elevadas, o benefício da sonegação aumentaria mais rapidamente do que os custos. Ademais, regras fixas de punição podem fazer com que a evasão seja rentável somente quando as alíquotas são suficientemente elevadas. Para captar esse efeito analisamos o impacto marginal de aumentos nas alíquotas tarifárias sobre a evasão, ao longo de diferentes níveis tarifários. ${ }^{7}$

Os resultados obtidos corroboram essa suposição. De fato, o impacto das alíquotas sobre a evasão é positivo e significante apenas para alíquotas acima de $12 \%$. Abaixo desse nível tarifário, o custo de sonegar supera os beneficios de fazê-lo, conforme sugerido pelo coeficiente negativo, não-significante, atrelado à alíquota referente ao $1^{\circ}$ intervalo quartílico.

Tabela 2 - Impactos das Alíquotas sobre a Evasão Fiscal - 1998-2003

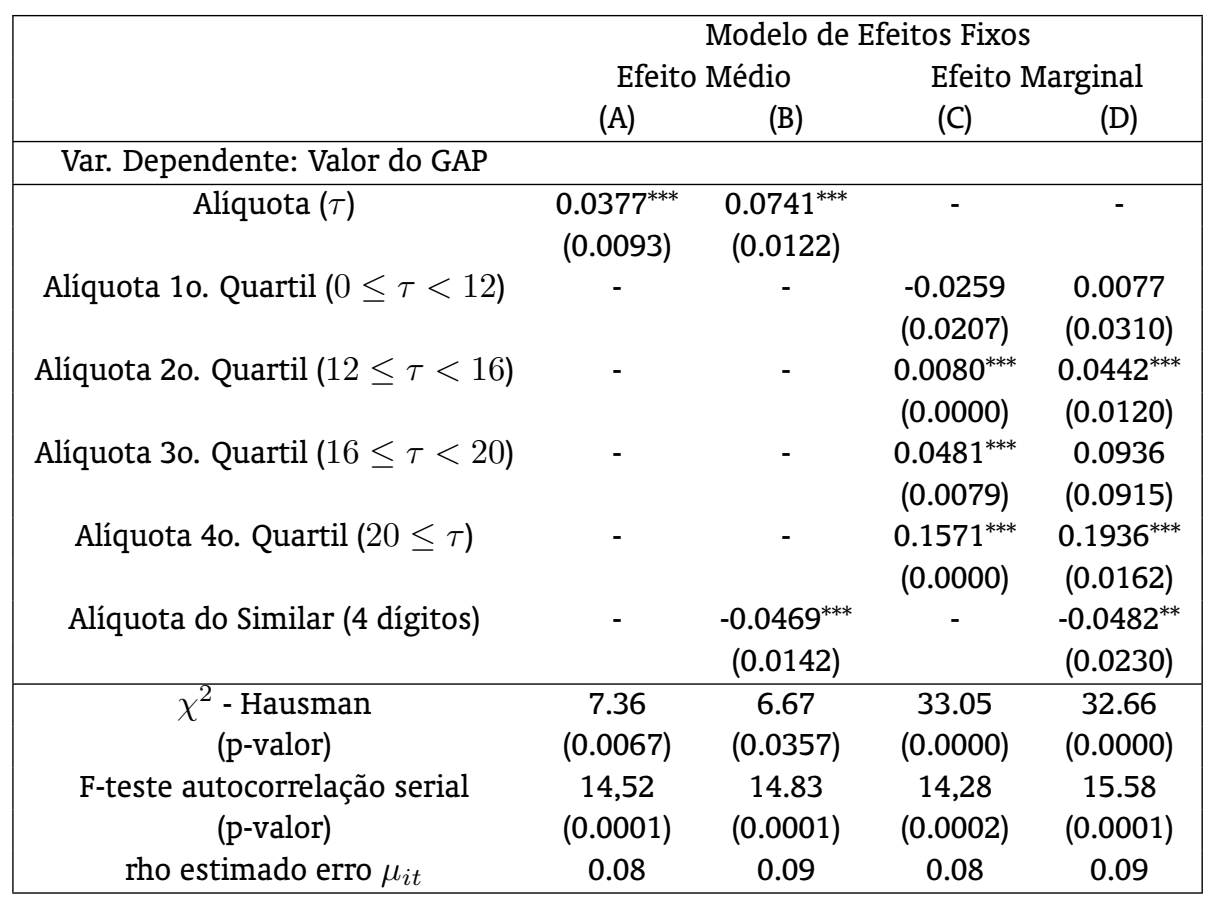

Nota: N. obs $=23467 .^{* * *},{ }^{* *},{ }^{*}$ indicam significância a $1 \%, 5 \%$ e $10 \%$, respectivamente. Erros-padrão robustos em parênteses.

\footnotetext{
${ }^{7}$ De fato, testamos também uma especificação quadrática para captar não-linearidades, mas essa se mostrou muito restritiva.
} 
Porém, para tarifas acima de $12 \%$, a evasão cresce, de forma significativa, como pode ser comprovado examinando-se os coeficientes estimados para os demais intervalos quartílicos. Assim, para alíquotas superiores a $20 \%$, o coeficiente (0.1571) é quase quatro vezes superior àquele referente à alíquota média (0.0377). Tal comportamento reforça a hipótese de que a evasão será tanto maior quanto maior for o custo de oportunidade da tributação. Como no caso anterior, na especificação (D), os coeficientes atrelados aos diferentes níveis tarifários são mais elevados quando se leva em conta a evasão via classificação incorreta, mediante a inclusão da variável alíquota média do similar $\left(\tau_{\text {sim }}\right)$.

Tabela 3 - Impactos das Alíquotas sobre a Evasão Fiscal, Incorporando o Efeito de Classificação Incorreta $-1998-2003$

\begin{tabular}{|c|c|c|c|c|}
\hline & \multicolumn{4}{|c|}{ Modelo Efeitos Fixos } \\
\hline & \multicolumn{2}{|c|}{ Efeito Médio } & \multicolumn{2}{|c|}{ Efeito Marginal } \\
\hline & (A) & (B) & (C) & (D) \\
\hline \multicolumn{5}{|l|}{ Var. Dependente: Valor do GAP } \\
\hline Alíquota $(\tau)$ & $\begin{array}{c}0.0768^{* * *} \\
(0.0136)\end{array}$ & $\begin{array}{c}0.0775^{* * *} \\
(0.0125)\end{array}$ & - & - \\
\hline Alíquota 1o. Quartil $(0 \leq \tau<12)$ & - & - & $\begin{array}{c}0.0081 \\
(0.0226)\end{array}$ & $\begin{array}{c}0.0082 \\
(0.0222)\end{array}$ \\
\hline Alíquota 2o. Quartil $(12 \leq \tau<16)$ & - & - & $\begin{array}{l}0.0501^{* *} \\
(0.0194)\end{array}$ & $\begin{array}{c}0.0499^{*} \\
(0.0267)\end{array}$ \\
\hline Alíquota 3o. Quartil $(16 \leq \tau<20)$ & - & - & $\begin{array}{c}0.0962^{* * *} \\
(0.0105)\end{array}$ & $\begin{array}{c}0.0963^{* * *} \\
(0.0107)\end{array}$ \\
\hline Alíquota 4o. Quartil $(20 \leq \tau)$ & - & - & $\begin{array}{c}0.1850^{* * *} \\
(0.0218)\end{array}$ & $\begin{array}{c}0.1859^{* * *} \\
(0.0222)\end{array}$ \\
\hline Alíquota do Similar (4 dígitos) & $\begin{array}{c}-0.0455^{* * *} \\
(0.0101)\end{array}$ & $\begin{array}{c}-0.0448^{* * *} \\
(0.0065)\end{array}$ & $\begin{array}{r}-0.04745 \\
(0.0931)\end{array}$ & $\begin{array}{c}-0.0472 \\
(0.0948)\end{array}$ \\
\hline Amplitude da Alíquota (4 dígitos) & $\begin{array}{c}0.0325^{* * *} \\
(0.0105)\end{array}$ & - & $\begin{array}{c}0.0173^{*} \\
(0.0094)\end{array}$ & - \\
\hline Desvio-padrão da Alíquota (4 dígitos) & - & $\begin{array}{c}0.0756^{* * *} \\
(0.0105)\end{array}$ & - & $\begin{array}{c}0.0363^{* * *} \\
(0.0777)\end{array}$ \\
\hline$\chi^{2}-$ Hausman & 40.61 & 37.91 & 65.90 & 59.14 \\
\hline (p-valor) & 0.000 & $(0.0000)$ & 0.000 & $(0.0000)$ \\
\hline F-teste autocorrelação serial & 14.69 & 14.71 & 14.52 & 14.54 \\
\hline (p-valor) & 0.000 & 0.000 & 0.000 & $(0.0001)$ \\
\hline rho estimado erro $\mu_{i t}$ & 0.09 & 0.09 & 0.08 & 0.09 \\
\hline
\end{tabular}

Nota: N. obs $=23467 .{ }^{* * *},{ }^{* *},{ }^{*}$ indicam significância a $1 \%, 5 \%$ e $10 \%$, respectivamente. Erros-padrão robustos em parênteses.

No tocante ao impacto da complexidade do sistema tarifário sobre os níveis de evasão fiscal, como dito anteriormente, testamos, aqui duas proxies diferentes para avaliar a dispersão do sistema tarifário: o desvio-padrão das alíquotas tarifárias $\left(\sigma_{i}^{2}\right)$ e, a variável $\tau$ - amplit, que mede a amplitude das tarifas. Lembramos que essas variáveis são ambas definidas dentro de cada categoria de quatro dígitos, do sistema SH. Os resultados obtidos estão expostos na Tabela 3. Confirmando a argumentação teórica, a complexidade do sistema tarifário, aproximada pelo desvio padrão e pela amplitude das alíquotas, favorece a sonegação. Em todas as especificações do modelo, os coeficientes positivos e significantes atrelados a essas variáveis mostram que tanto uma maior amplitude das alíquotas como sua maior dispersão, contribuem para aumentar o gap de evasão. Portanto, regras de tributação mais complexas -

RBE Rio de Janeiro $\quad$ v. 62 n. 1/p. 77-93 Jan-Mar 2008 
que incluem distinções detalhadas entre produtos bem como a existência de isenções e regimes especiais que modificam a forma de tributação - dificultam a tarefa da administração tributária e facilitam a evasão fiscal. Note-se, ainda, que a introdução das variáveis acima citadas não altera, em magnitude e significância, os coeficientes das variáveis alíquota média do produto $(\tau)$ e alíquota média do similar $\left(\tau_{\text {sim }}\right)$.

Por fim os resultados da Tabela 4 apresentam, além das variáveis utilizadas nas tabelas anteriores, a variável $\theta_{i}$, que mensura a participação relativa do i-ésimo produto no comércio bilateral total. O sinal positivo do coeficiente atrelado a essa variável sinaliza que quanto maior o fluxo comercial de determinado produto, maior a evasão, mensurada pela Equação (6). Haveria, portanto, efeitos economias de escala na evasão. Isto se deve provavelmente ao fato de que, para os produtos mais comercializados, os importadores teriam mais experiência em burlar a legislação tributária, o que facilitaria a evasão. Ademais, aceitando-se a hipótese de que os maiores setores da economia são aqueles que mais importam, podemos fazer uma analogia com o modelo teórico A-S, de acordo com o qual, quanto mais rico o indivíduo, maior o estímulo à evasão. Vale ressaltar que o modelo é bastante robusto, já que os coeficientes das variáveis alíquota média do produto (ou splines da alíquota a 6 dígitos) e alíquota media do similar não se alteram, mais uma vez, com a inclusão desse controle.

A princípio, a possibilidade de evasão por classificação incorreta (mislabeling) também poderia ser medida pela variável alíquota mínima do similar. Estimamos modelos incluindo a alíquota mínima do similar ao invés da alíquota média do similar, e modelos incluindo ambas as variáveis simultaneamente. Apresentamos tais resultados na Tabela 5. Na coluna (A) incluímos ambas a alíquota média do similar e a alíquota mínima do similar, e isso reduz o coeficiente associado ao subfaturamento e aumenta o associado à classificação incorreta para outra alíquota que não a mínima. Tal comportamento é justificável na medida em que a classificação incorreta pela alíquota mínima é mais óbvia e pode aumentar as chances de detecção. Ao adicionar uma medida de complexidade do sistema a essa especificação (colunas B e E) esse resultado é ainda mais forte, indicando que existem alternativas de evasão por classificação incorreta bastante atrativas e não tão visadas pelas autoridades fiscais. Ao incluir a alíquota mínima do similar ao invés da alíquota média do similar (colunas D e G) o coeficiente da alíquota média do produto a 6 dígitos, bem como o da Alíquota Mínima do Similar perdem a significância estatística e a evasão passa a ser explicada primordialmente pela complexidade do sistema tributário.

Com o intuito de estudar os efeitos de interações na evasão por subfaturamento e por classificação incorreta (mislabeling), mensuradas, respectivamente pelas variáveis Alíquota Média e Alíquota Média do Similar, estimamos modelos com a variável Alíquota Média multiplicada pelo desvio-padrão de Alíquota Média do Similar (resultados reportados nas colunas C e F da Tabela 5). Caso o subfaturamento aumentasse com a redução na possibilidade de classificação incorreta o coeficiente dessa variável seria negativo. Em nossos modelos esses coeficientes não são significativamente diferentes de zero. 
Tabela 4 - Impactos das Alíquotas sobre a Evasão Fiscal, Incorporando o Efeito de Classificação Incorreta e Amplitude das Alíquotas - 1998-2003

\begin{tabular}{|c|c|c|c|c|}
\hline & \multicolumn{4}{|c|}{ Modelo Efeitos Fixos } \\
\hline & \multicolumn{2}{|c|}{ Efeito Médio } & \multicolumn{2}{|c|}{ Efeito Marginal } \\
\hline & (A) & (B) & (C) & (D) \\
\hline \multicolumn{5}{|l|}{ Var. Dependente: Valor do GAP } \\
\hline \multirow[t]{2}{*}{ Alíquota $(\tau)$} & $0.0776^{* * *}$ & $0.0781^{* * *}$ & - & - \\
\hline & $(0.0128)$ & $(0.0124)$ & & \\
\hline \multirow[t]{2}{*}{ Alíquota 1o. Quartil $(0 \leq \tau<12)$} & - & - & 0.0166 & 0,02 \\
\hline & & & $(0.0363)$ & $(0.0351)$ \\
\hline \multirow[t]{2}{*}{ Alíquota 2o. Quartil $(12 \leq \tau<16)$} & - & - & 0.0481 & 0.0479 \\
\hline & & & $(0.0616)$ & $(0.0309)$ \\
\hline \multirow[t]{2}{*}{ Alíquota 3o. Quartil $(16 \leq \tau<20)$} & - & - & $0.0963^{* * *}$ & $0.0964^{* * *}$ \\
\hline & & & $(0.0202)$ & $(0.0256)$ \\
\hline \multirow[t]{2}{*}{ Alíquota 4o. Quartil $(20 \leq \tau)$} & - & - & $0.1847^{* * *}$ & $0.1856^{* * *}$ \\
\hline & & & $(0.0212)$ & $(0.0204)$ \\
\hline \multirow[t]{2}{*}{ Alíquota do Similar (4 dígitos) } & $-0.0460^{* * *}$ & $-0.0454^{* * *}$ & $-0.0479^{* * *}$ & $-0.0477^{* * *}$ \\
\hline & $(0.0084)$ & $(0.0062)$ & $(0.0088)$ & $(0.0100)$ \\
\hline \multirow[t]{2}{*}{ Amplitude da Alíquota (4 dígitos) } & $0.0305^{* *}$ & - & 0.0150 & - \\
\hline & $(0.0120)$ & & $(0.0374)$ & \\
\hline \multirow[t]{2}{*}{ Desvio-padrão da Alíquota (4 dígitos) } & - & $0.0711^{* * *}$ & - & 0.0310 \\
\hline & & $(0.0096)$ & & $(0.0397)$ \\
\hline \multirow[t]{2}{*}{ Participação \% nas Exportações } & $2.2405^{* * *}$ & $2.2427^{* * *}$ & $2.1981^{* * *}$ & $2.2006^{* * *}$ \\
\hline & $(0.0037)$ & $(0.0038)$ & $(0.0298)$ & (0.0299) \\
\hline \multirow{2}{*}{$\chi^{2}$ - Hausman } & 36.80 & 34.25 & 59.56 & 53,11 \\
\hline & 0.000 & 0.000 & 0.000 & 0.000 \\
\hline \multirow{2}{*}{$\begin{array}{c}\text { F-teste autocorrelação serial } \\
\text { (p-valor) }\end{array}$} & 14.80 & 14.82 & 14.64 & 14,66 \\
\hline & 0.000 & 0.000 & 0.000 & 0.000 \\
\hline rho estimado erro $\mu_{i t}$ & 0.09 & 0.09 & 0.09 & 0,09 \\
\hline
\end{tabular}

Nota: N. obs $=23467 .{ }^{* *},{ }^{* *},{ }^{*}$ indicam significância a $1 \%, 5 \%$ e $10 \%$, respectivamente. Erros-padrão robustos em parênteses. 


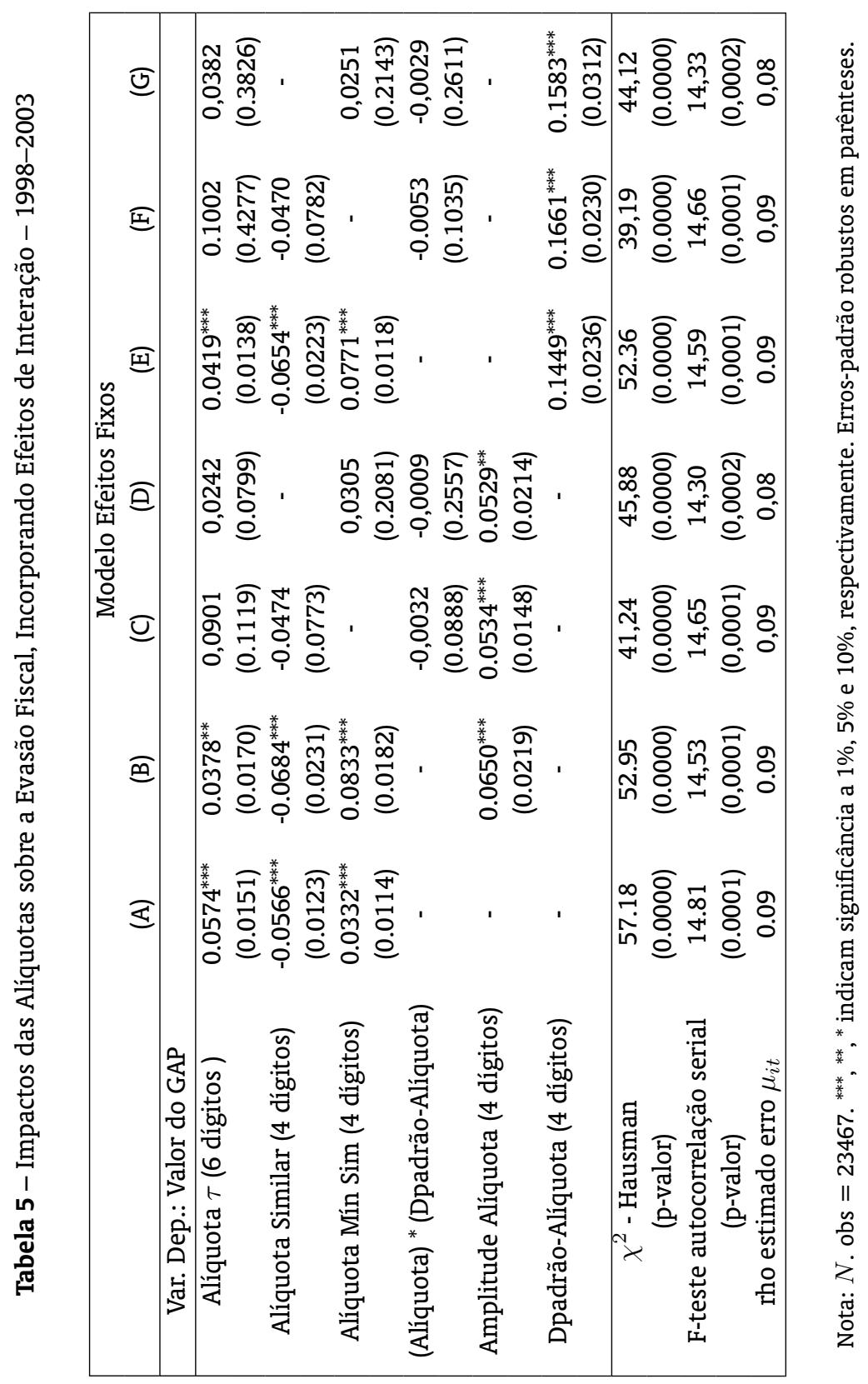


Uma questão importante é saber em que medida a receita tarifária é afetada pelas variações das alíquotas do imposto de importação. Isto equivale a investigar a maginitude e o sinal da inclinação da curva de Laffer. Para tal, lembremos que a receita tarifária (R) escreve-se como:

$$
R=\tau M
$$

A inclinação da curva de Laffer é, pois, dada pela expressão:

$$
\frac{d R}{d \tau}=M+\tau\left[\left(\frac{d M}{d \tau}\right)\right]
$$

A partir da Equação (2), é possível estimar esse impacto, no âmbito do nosso trabalho Diferenciando a Equação (2) em relação à $\tau$, obtém-se:

$$
\frac{\frac{d(M)}{d \tau}}{M}=\frac{\frac{d(E)}{d(\tau)}}{E}-\beta_{1}
$$

A Equação (9) mostra, pois, que um aumento da alíquota tarifária diminui as importações reportadas de duas maneiras distintas: (i) reduzindo efetivamente o volume importado (primeiro termo do lado direito da equação); e (ii) reduzindo o volume de importações declarado junto à aduana (dado pelo segundo termo do lado direito da equação $\left(-\beta_{1}\right)$. Apesar de não existir estimação direta para o primeiro termo do lado direito da Equação (9), é razoável supor que ele assuma um valor menor ou igual a zero, uma vez que em geral um aumento de alíquota reduz a quantidade demandada das exportações (importações). Reescrevendo a expressão (9), temos que:

$$
\frac{d M}{d \tau}=M\left[\frac{d E}{d(\tau)} \frac{1}{E}-\beta_{1}\right]
$$

Utilizando (10) em (8) e re-arrumando os termos:

$$
\frac{d R}{d \tau}=M+\tau M\left[\left(\frac{d E}{d \tau}\right)\left(\frac{1}{E}\right)\right]-\beta_{1}
$$

Então, se a expressão (11) for negativa, aumentos nas alíquotas conduzem a reduções da arrecadação. Isso ocorrerá quando,

$$
\tau>\frac{1}{\left[\left(\frac{d E}{d \tau}\right)\left(\frac{1}{E}\right)\right]-\beta_{1}}
$$

Podemos agora definir o nível crítico da alíquota a partir do qual a curva de Laffer se torna negativamente inclinada. Desconsiderando o termo $\left[\left(\frac{d E}{d \tau}\right)\left(\frac{1}{E}\right)\right]$, para $\beta_{1}$ igual a 0,0377 (modelo de referência, Tabela 2, coluna A), isto ocorre quando as alíquotas são superiores a 26,5\% (1/0.0377). A partir desse valor tarifário, um aumento de um ponto percentual nas alíquotas reduzirá as importações declaradas em mais de um ponto percentual diminuindo, assim, a arrecadação. A Tabela 6 mostra esses valores para os diferentes modelos testados. Note-se, em primeiro lugar, que quando consideramos a possibilidade de evasão via classificação incorreta - colunas C a E - tanto as alíquotas médias como as alíquotas marginais, a partir das quais a arrecadação se reduz são bem menores, situando-se em torno de $13 \%$. Esse limiar será diminuído quanto se leva em conta o termo $\left(\frac{d E}{d \tau}\right)\left(\frac{1}{E}\right)$, cujo sinal esperado é negativo. 

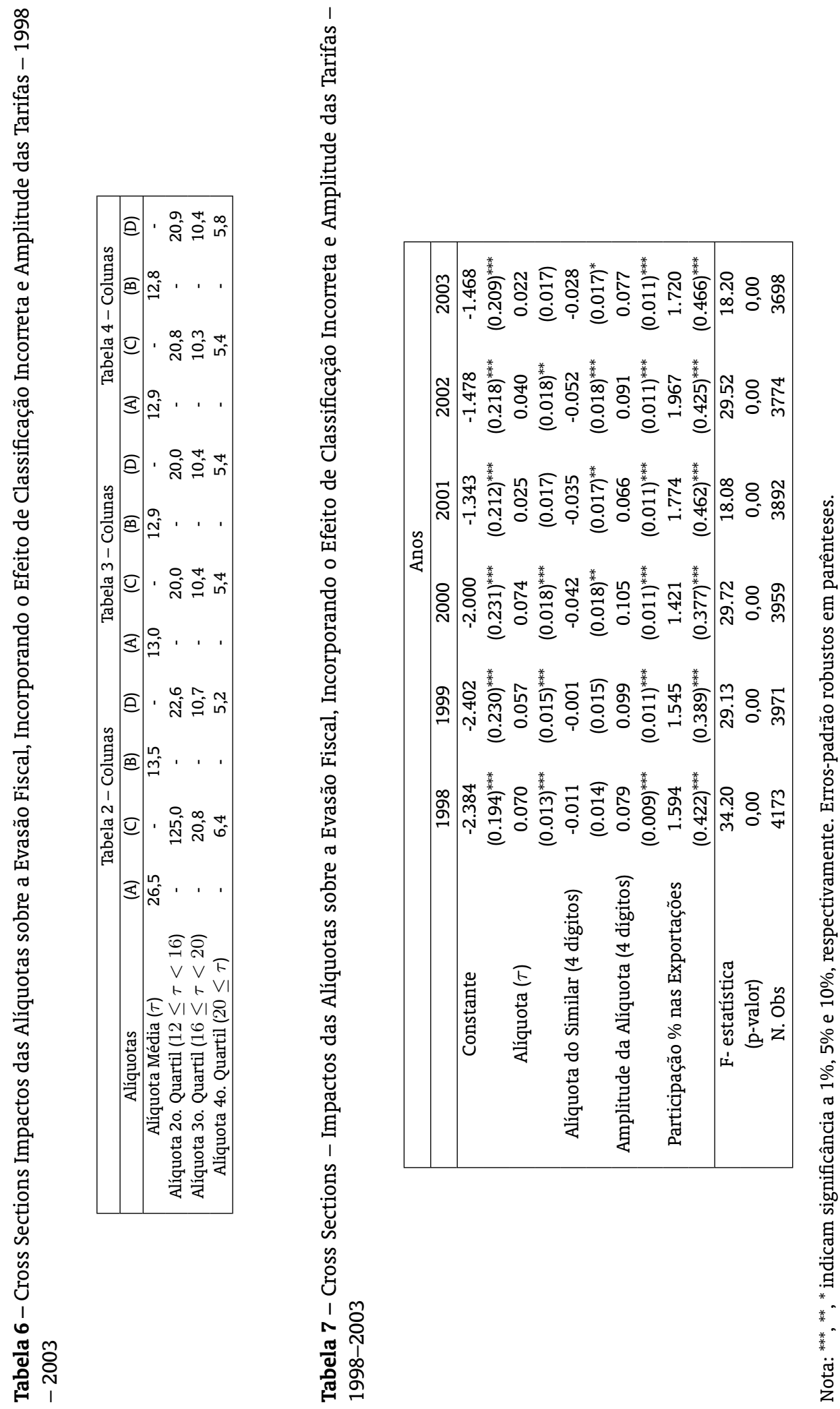
Como, no Brasil, a alíquota média do produto que incide sobre as importações varia entre $13,7 \%$ e $16.4 \%$, esse resultado indica que, para vários produtos, podemos já estar na parte descendente da curva de Laffer, onde a elasticidade das importações brasileiras oriundas dos EUA é superior à unidade. Quando se leva em conta os efeitos marginais (colunas (C) e (D), das Tabelas 2 a 4), os níveis críticos das alíquotas diminuem substancialmente com a magnitude das mesmas. Assim, para os produtos cujas alíquotas situam-se no último intervalo quartilíco, qualquer aumento de alíquotas reduzirá a arrecadação com esses produtos, visto que as alíquotas do intervalo são superiores a 6,4\% (o maior nível crítico para esse intervalo). Já no terceiro intervalo quartílico, apenas no modelo que não considera a evasão por classificação incorreta (coluna C da Tabela 2), aumentos tarifários não levariam a diminuição na arrecadação. Somente os produtos com níveis tarifários situados no primeiro e segundo intervalos quartílicos ainda estariam na parte ascendente da curva de Laffer, na qual aumentos das alíquotas representariam aumentos na arrecadação tributária.

Ressalte-se, ainda, que isso ocorre apesar de as importações brasileiras provenientes dos Estados Unidos serem, majoritariamente, produtos manufaturados, dos quais parcela significativa são insumos ou bens de capital, cuja demanda é relativamente inelástica.

Por fim, é interessante ver em que medida os impactos acima descritos comportam-se ao longo do tempo. Para tanto, apresentamos na Tabela 7, resultados das regressões em cross-section para o modelo completo (Tabela 4, coluna A). Nota-se, em primeiro lugar, que o impacto positivo das tarifas sobre a evasão se mantém em todos os anos e atinge seu pico em 2000. Já o coeficiente atrelado à variável alíquota média do similar somente passa a ser significante a partir de 2000 sugerindo, assim, que a evasão por classificação incorreta pode ser um fenômeno relativamente recente, que alcança seu máximo em 2002. Ademais, no ano de 2000, a evasão por meio de subfaturamento é a maior para o período observado. Corroborando os resultados da análise de dados de painel, para todos os anos analisados, a complexidade do sistema tributário conduz a maior evasão fiscal, quando se controla para as demais variáveis. Vale ressaltar ainda, que visando estudar o comportamento da evasão fiscal no tempo, também estimamos os modelos de efeitos fixos com a inclusão de dummies temporais. Tais variáveis indicam que a evasão tem diminuído no período analisado. Com a inclusão dessas variáveis, o coeficiente associado à alíquota média do produto $(\tau)$ diminui em magnitude, passando de 0,077 para 0,045 no modelo completo da Tabela 4 , coluna $\mathrm{A}$, enquanto o coeficiente associado à alíquota média do similar aumenta em valor absoluto de $-0,046$ para $-0,054$ e o coeficiente associado à amplitude $d a$ alíquota decresce marginalmente de 0,031 para 0,026.

\section{CONCLUSÃO}

Este trabalho, baseado na abordagem de Fisman e Wei (2004), em que as discrepâncias entre as informações de exportações na origem e de importações no destino servem como proxy para a sonegação, buscou mensurar a influência das alíquotas do imposto de importação sobre a evasão fiscal, nas importações brasileiras oriundas dos Estados Unidos. Os resultados obtidos permitem concluir que as alíquotas tarifárias influenciam, significativamente, a evasão sob suas diferentes formas: subfaturamento e classificação incorreta de mercadorias. Alíquotas mais elevadas estimulam a prática de evasão e se refletem em gaps maiores, uma vez que o custo de oportunidade de declarar corretamente as importações aumenta. Estes resultados corroboram o modelo básico de evasão proposto por Allingham (1972) e se insere no debate sobre a relação entre a magnitude das alíquotas e o potencial para evasão.

Nossos resultados mostram, ainda, a existência de não-linearidades na relação entre alíquotas e evasão. Nos vários modelos testados, esse efeito cresce com a magnitude das tarifas, sugerindo que maiores alíquotas aumentam o custo de oportunidade da tributação e geram maiores incentivos para a sonegação.

Com respeito à relação entre o nível de complexidade do sistema tributário e a evasão, nosso trabalho sugere que uma maior diferenciação entre alíquotas, dificulta a administração tarifária e aumentas 
os níveis de evasão. Isso mesmo considerando que nossas proxies para a complexidade do sistema tarifário não captam todas as particularidades desse sistema, incluindo-se aí as diferentes isenções e regimes especiais.

No tocante à participação relativa de determinado produto no total importado, verificou-se que esta participação tem uma relação direta e positiva com a sonegação. Ou seja, quanto maior a importação de determinado produto maior a sonegação. Este resultado, de certa forma, também encontra amparo na teoria, uma vez que quanto mais se importa, considerando um mesmo importador, maior o custo de oportunidade de recolher corretamente o imposto de importação.

Os resultados acima reportados são promissores, principalmente no que se refere ao impacto das tarifas sobre a evasão fiscal, uma vez que os coeficientes estimados mostraram-se consistentes e significantes. Em particular, nosso trabalho mostra que a liberalização do comércio, que vem ocorrendo no Brasil, ao reduzir as alíquotas, reduz também o incentivo à fraude fiscal e, portanto, não se traduz, necessariamente, em menor arrecadação. Por fim, uma extensão natural desse trabalho é replicar a proposta aqui apresentada para outros parceiros comerciais, o que permitiria identificar se a sonegação nas importações assume características particulares, dependendo do parceiro comercial, ou se tem um padrão comportamental aleatório.

\section{Referências Bibliográficas}

Allingham, Michael G. and Sandmo, A. (1972). Income tax evasion: A theoretical analysis. Journal of Public Economics, 1(3-4):323-338. Available at http://ideas.repec.org/a/eee/pubeco/ v1y1972i3-4p323-338.html.

Alm, J., Bahl, R., \& Murray, M. N. (1991). Tax base erosion in developing countries. Economic Development and Cultural Change, 39(4):849-72. Available at http://ideas .repec.org/a/ucp/ecdecc/ v39y1991i4p849-72.html.

Andreoni, J. (1992). Irs as loan shark tax compliance with borrowing constraints. Journal of Public Economics, 49(1):35-46. Available at http: //ideas.repec.org/a/eee/pubeco/v49y1992i1p35-46. html.

Anson, J., Cadot, O., \& Olarreaga, M. (2003). Tariff evasion and customs corruption: Does psi help? CEPR Discussion Papers 4167, C.E.P.R. Discussion Papers. Available at http://ideas.repec.org/ $\mathrm{p} / \mathrm{cpr} / \mathrm{ceprdp} / 4167 . \mathrm{html}$.

Arndt, C. \& Tarp, F. (2004). On trade policy reform and the missing revenue: an application to mozambique. Discussion Papers 04-19, University of Copenhagen. Department of Economics (formerly Institute of Economics). Available at http://ideas. repec. org/p/kud/kuiedp/0419.html.

Burgess, R. \& Stern, N. (1993). Taxation and development. Journal of Economic Literature, 31(2):762-830. available at http://ideas.repec.org/a/aea/jeclit/v31y1993i2p762-830.html.

de Melo, J., Roland-Holst, D., \& Haddad, M. (1992). Tax evasion and tax reform in a low income economy : General equilibrium estimates for madagascar. Policy Research Working Paper Series 918, The World Bank. Available at http://ideas.repec.org/p/wbk/wbrwps/918.html.

De Wulf, L. (1981). Statistical analysis of under and over invoicing of imports. Journal of public economics, 8:303-323.

Feenstra, R. \& Hanson, G. (2000). Aggregation bias in the factor content of trade: Evidence from U.S. manufacturing. American Economic Review, 90(2):155-160. Available at http: //ideas .repec .org/ a/aea/aecrev/v90y2000i2p155-160.html. 
Fisman, R. \& Wei, S.-J. (2004). Tax rates and tax evasion: Evidence from "missing imports" in China. Journal of Political Economy, 112(2):471-500. Available at http://ideas.repec.org/a/ucp/jpolec/ v112y2004i2p471-500.html.

Hindriks, J., Keen, M., \& Muthoo, A. (1999). Corruption, extortion and evasion. Journal of Public Economics, 74(3):395-430. Available at http://ideas.repec.org/a/eee/pubeco/ v74y1999i3p395-430.html.

Kaplow, L. (1996). How tax complexity and enforcement affect the equity and efficiency of the income tax. NBER Working Papers 5391, National Bureau of Economic Research, Inc. Available at http: //ideas.repec.org/p/nbr/nberwo/5391.html.

Marrelli, M. \& Martina, R. (1988). Tax evasion and strategic behaviour of the firms. Journal of Public Economics, 37(1):55-69. Available at http://ideas.repec.org/a/eee/pubeco/ v37y1988i1p55-69.html.

Mayshar, J. (1991). Taxation with costly administration. Scandinavian Journal of Economics, 93(1):75-88. Available at http://ideas.repec.org/a/bla/scandj/v93y1991i1p75-88.html.

Pritchett, L. \& Sethi, G. (1994). Tariff rates, tariff revenue, and tariff reform: Some new facts. World Bank Economic Review, 8(1):1-16. Available at http://ideas.repec.org/a/oup/wbecrv/ v8y1994i1p1-16.html.

Slemrod, J. \& Bakija, J. (1998). Taxing ourselves. A citizen's guide to the great debate over tax reform. The MIT Press, Cambridge, MA.

Slemrod, J. \& Yitzhaki, S. (2002). Tax avoidance, evasion, and administration. In Auerbach, A. J. \& Feldstein, M., editors, Handbook of Public Economics, volume 3 of Handbook of Public Economics, chapter 22 , pages 1423-1470. Elsevier. Available at http://ideas.repec.org/h/eee/pubchp/3-22.html.

Tsikata, Y. M. (1999). Southern africa: trade, liberalization, and implications for a free trade area. Trade and Industrial Policy Secretariat (TIPS) Annual Forum.

Wooldridge, J. M. (2002). Econometric Analysis of Cross Section and Panel Data. The MIT Press, Cambridge, MA.

Yitzhaki, S. (1974). A note on optimal income tax evasion: a theoretical analysis. Journal of public economics, 3:201-202.

Yitzhaki, S. (1979). A note on optimal taxation and administrative aosts. American Economic Eeview, 69(2):475-480 